\title{
Uncovering the roles of organics on solid solution nucleation and growth
}

\author{
YANDI HU $1 * 1$, NING DENG ${ }^{1}$, ANDREW G. \\ STACK $^{2}$, JULIANE WEBER, ${ }^{2}$ BO CAO $^{1}$, AND \\ JAMES DEYOREO ${ }^{3}$
}

${ }^{1}$ Department of Civil \& Environmental Engineering, University of Houston, Houston, TX 77004

(*Correspondence: yhu11@uh.edu)

${ }^{2}$ Chemical Science Division,

Oak Ridge National Laboratory, Oak Ridge, Tennessee 37831

${ }^{3}$ Physical Sciences Division, Pacific Northwest National Laboratory, Richland, WA 99354

Solid solutions, i.e. solid phases with substitutional impurities in their structures like $\left(\mathrm{Ba}_{\mathrm{x}}, \mathrm{Sr}_{\mathrm{y}}, \mathrm{Ra}_{1-\mathrm{x}-\mathrm{y}}\right)\left(\mathrm{SO}_{4}\right.$, $\mathrm{SeO}_{4}{ }_{1-\mathrm{x}}$ ), have wide occurrence in natural systems. Many of them have compositions (i.e., $x, y$ ) violating thermodynamic predictions based on bulk solution conditions under which they form. Such paradoxes are often associated with organicrich environments, however, the roles of organics in controling solid solution nucleation and growth are far from well known. Here a suite of state-of-the-art techniques and theoretical calculations will be integrated to understand such processes. In situ grazing-incidence small angle X-ray scattering (GISAXS) are used to measure nucleation and growth rates of $(\mathrm{Ba}, \mathrm{Sr}, \mathrm{Ra})\left(\mathrm{SO}_{4}, \mathrm{SeO}_{4}\right)$ on organic films with a range of compositions; and homogeneous precipitation of solid solutions in solution with dissolved organics was also investigated as comparison. Organic film interactions with inorganic species were investigated and nucleation and growth models are tested to identify the controlling mechanisms and predict the size and composition of solid solution precipitates. These new insights learnt revised our understanding of solid solution formation and provide mechanistic answers to current mysteries in nature, as well as enable manipulation of solid solution formation by tuning the chemical environment via organic-water interfaces. 